\title{
New evidence for truly gregarious behavior of ornithopods and solitary hunting by a theropod
}

\author{
${ }^{1}$ Department of Earth and Environmental Sciences, Pukyong National University, 48513 Busan, Republic of Korea; *Corresponding author, \\ E-mail:paikis@pknu.ac.kr \\ ${ }^{2}$ Gematek Co. Ltd. Busan 48071, Republic of Korea
}

(Received: April 7, 2020; Revised accepted: June 11, 2020)

https://doi.org/10.18814/epiiugs/2020/020069

Multiple subparallel dinosaur trackways closely associated with a solitary theropod trackway occur in the Late Cretaceous deposits at Yugok-dong in Ulsan City, Korea. The trackway-bearing deposits are sheetflood deposits and are well-lithified to preserve the footprints. The paleoenvironment of trackway deposits is interpreted as a lake margin where microbial mats formed under semi-arid paleoclimatic conditions. The unique features of these dinosaur trackways are 1) preservation of transformed skin impressions in every footprint of multiple trackways indicating nearly simultaneous trackway formation, 2) occurrence of multiple trackways representing three kinds of ornithopods, and 3) close association of a theropod trackway with the ornithopod trackway. This study reports the another discovery to support the gregarious travelling of ornithopod dinosaurs and solitary hunting of theropods for herbivorous dinosaurs by the occurrence of simultaneously formed multiple trackways of ornithopods and one theropod trackway. This tracksite is very exceptional not only in preserving skin impressions in every footprint of six subparallel trackways but also in providing new evidence to support that different kinds of herbivorous dinosaurs moved together in the same direction to form a group. In addition, this tracksite suggests that solitary hunting was also present in non-avian dinosaurs as in modern tigers or leopards.

\section{Introduction}

A number of dinosaur footprints and trackways have been documented in the world, providing diverse information to understand dinosaurs from the aspects of ichnotaxonomy, size, walking speed, locomotion, habitat, behavior when hunting, mating, gathering, etc. (Falkingham et al., 2016). Among these studies gregarious behavior of herbivorous dinosaurs and theropods' hunting behavior have been interpreted on the basis that the studied footprints had been made simultaneously. In spite of such difficult unequivocal interpretation given taphonomic bias related to time-averaging, many examples of skeletal (Horner,
1982; Rogers, 1990; Zhao et al., 2007; Myers and Fiorillo, 2009) and ichnological (Lim et al., 1989; Pittman and Gillette, 1989; Lockley et al., 1992; Lockley, 1997; Lockley et al, 2002; Hwang et al., 2004; Lockley et al., 2006;; Jasinski, 2008; Lockley et al., 2012a; Razzolini et al., 2016) evidences show that dinosaurs were animals with gregarious behavior and that carnivorous dinosaurs hunted herbivores (Fastovsky and Smith, 2004; Roach and Brinkman, 2007; Li et al., 2008). However, fossil records convincingly ruling out time-averaging bias have scarcely been documented (McCrea et al., 2014).

If the multiple trackways were made at different times and if theropods' footprints associated with those of herbivorous dinosaurs were made at a separate time, such interpretations could not be accepted. In addition, the theories that theropod dinosaurs hunted prey in packs or as solos have been debated (Roach and Brinkman, 2007; McCrea et al., 2014).

In this paper, multiple subparallel dinosaur trackways closely associated with a solitary theropod trackway, in which transformed skin impressions are preserved in every footprint and testify to their coeval movement, are newly described. This study reports the first discovery to support the truly gregarious travelling of ornithopod dinosaurs and solitary hunting of theropods for herbivorous dinosaurs by the occurrence of simultaneously formed multiple trackways of ornithopods and one theropod trackway.

Although the results of this study are to envisage a snapshot of Earth history in a small area, this study provides additional data to understand that social and hunting behaviors of terrestrial vertebrates have little been changed throughout Earth history.

\section{Trackway-bearing Deposits}

The trackway site in Yugok-dong (Fig. 1a) has been designated as a natural heritage of Ulsan City, Korea. It is unique in that the site is located within city area and is surrounded by apartments and office buildings (Fig. 1a). At this site a small outcrop of Upper Cretaceous lake margin deposits belonging to the Sayeonri Formation of the Gyeongsang Supergroup (Choi, 1985) is exposed (Fig. 1b). The exposed beds with the multiple trackways (Fig. 1c,d) are approximately $120 \mathrm{~cm}$ thick, and inclined approximately 12 degrees. Above these beds another track deposit with a few indistinct footprints of sauropods and theropods is 

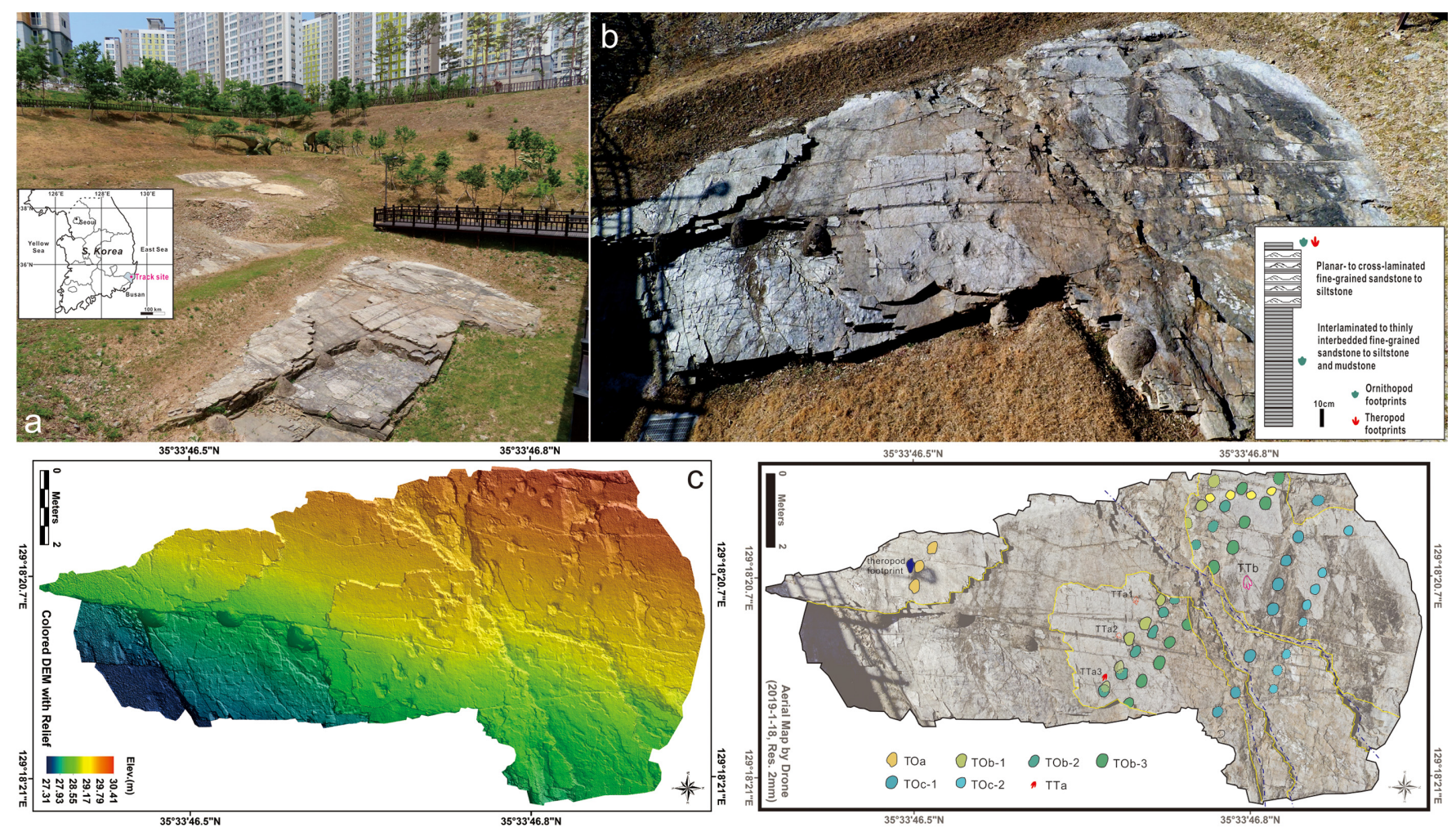

Figure 1. Geographical location and overall view of the study area (a), an aerial image of the outcrop by drone with inset of stratigraphic sections of the trackway-bearing deposits (b), DEM image of the outcrop (c), and a drawing map of dinosaur footprints on b (d). The insets were drawn using CorelDRAW X5 (www.coreldraw.com). TO are ornithopod trackways and TT is a theropod trackway.
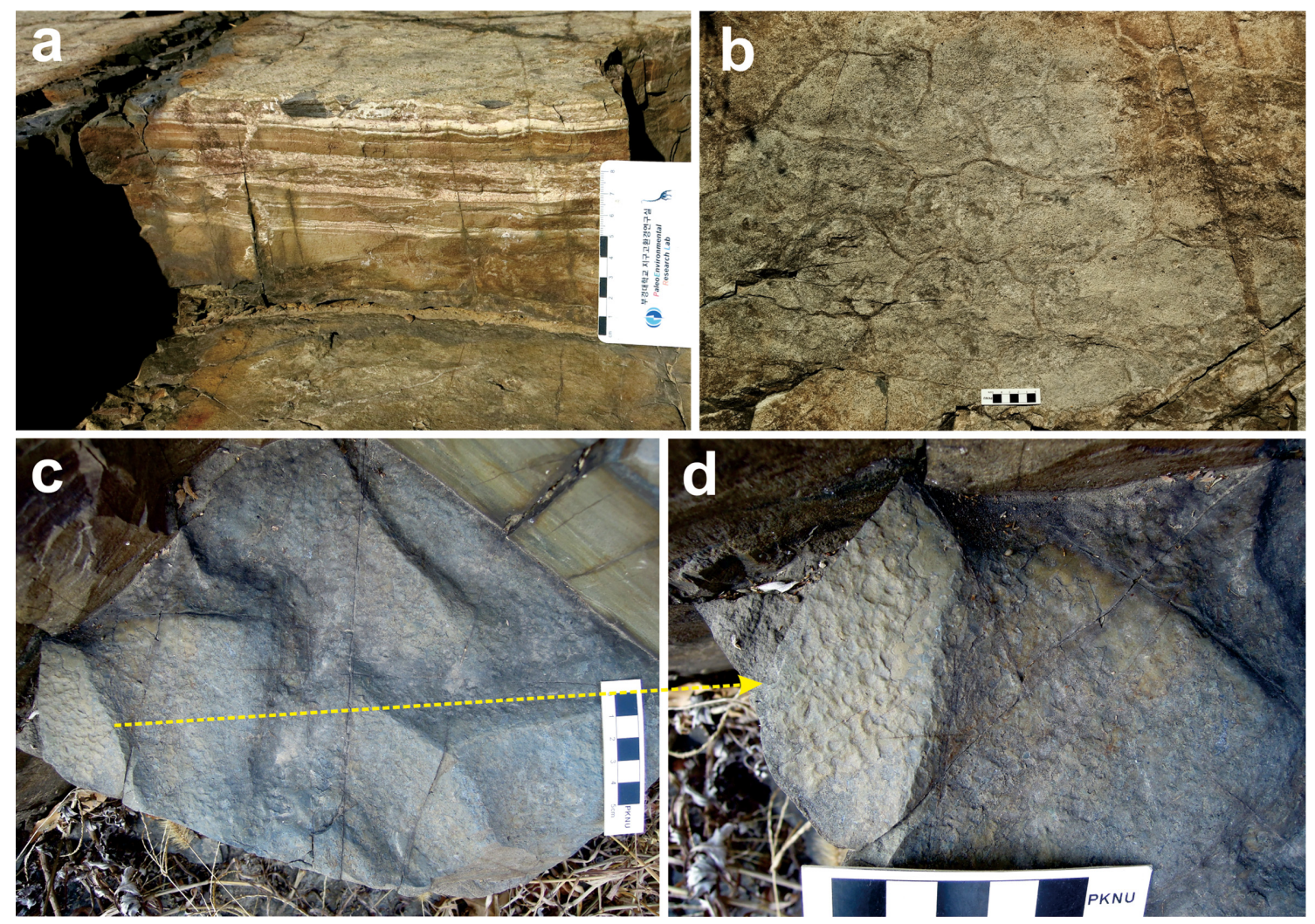

Figure 2. Sedimentological occurrences of the trackway-bearing deposits in study area. a. Sectional view of interlaminated fine-grained sandstone to siltstone and mudstone with desiccation cracks. b. Planar view of the polygonal desiccation cracks on the trackway-bearing deposits. c. Interference ripples formed on the planar-to cross-laminated fine-grained sandstone to siltstone beds below the trackway-bearing deposits. d. Close view of b showing the presence of rainprints. 
exposed in a small area. In general, the track-bearing deposits are well-lithified (hornfelsic) tuffaceous rocks preserving the footprints. The rocks represent sheetflood deposits consisting of interlaminated fine-grained sandstone to siltstone and mudstone beds with planar- to cross-laminated fine-grained sandstone to siltstone beds (Fig. 1b). Very thin beds of tuffaceous breccias are intermittently intercalated.

The subparallel dinosaur trackways are exposed on two successive bedding surfaces that were formed by a thrust fault with a few decimeters displacement. The track-bearing bed (a few cm thick) is composed of interlaminated fine-grained sandstone to siltstone and mudstone (Fig. 2a) overlying planar- to cross-laminated fine-grained sandstone to siltstone beds (10 to $30 \mathrm{~cm}$ thick). Polygonal desiccation cracks (Fig. 2b) transecting the footprints are present on the mudstone, and interference ripple marks associated with raindrop impressions are observed in places in the sandstone (Fig. 2c,d). The track-bearing mudstone consists of illitic clays with some kaolinite, chlorite, and smectite and feldspar and quartz silts (Fig. 3a). In the illitic and the smectitic clays honeycomb structure is well formed (Fig. 3b). Microbial records are observed in the rock slabs, thin sections (Fig. 3c) and field emission scanning electron microscopy (FE-SEM) images of the track-bearing mudstones (Fig. 3d).

The polygon sizes of the cracks in the trackway-bearing mudstone generally decrease towards the walking direction of the ornithopod trackways and the cracks gradually disappear. In addition, the depths of footprints generally decrease forwards, and the heel pad parts of footprints are more depressed than digital parts. The trackways are therefore interpreted having been made in the transitional zone of water saturation in a lake margin environment. In other words, the trackways were made on a lake margin (mudflat) when the dinosaurs were leaving the lake probably after drinking water. The paleoenvironment is interpreted as a lake margin where microbial mats could form under semi-arid conditions with alternation of wetting and drying periods. The lake area might have been influenced by occasional volcanic eruptions inducing earthquakes.

\section{Occurrences of the Trackways}

The unique features of the dinosaur trackways exposed in this site are 1) preservation of transformed skin impressions in every footprint of multiple trackways indicating nearly simultaneous trackway formation, 2) occurrence of multiple trackways representing three kinds of ornithopods (measurement for the trackways is summarized in Table 1), and 3) close association of a theropod trackway with the ornithopod trackway.

On the surfaces of the subparallel ornithopod trackways, distinct polygonal structures with positive relief are well-observed in every
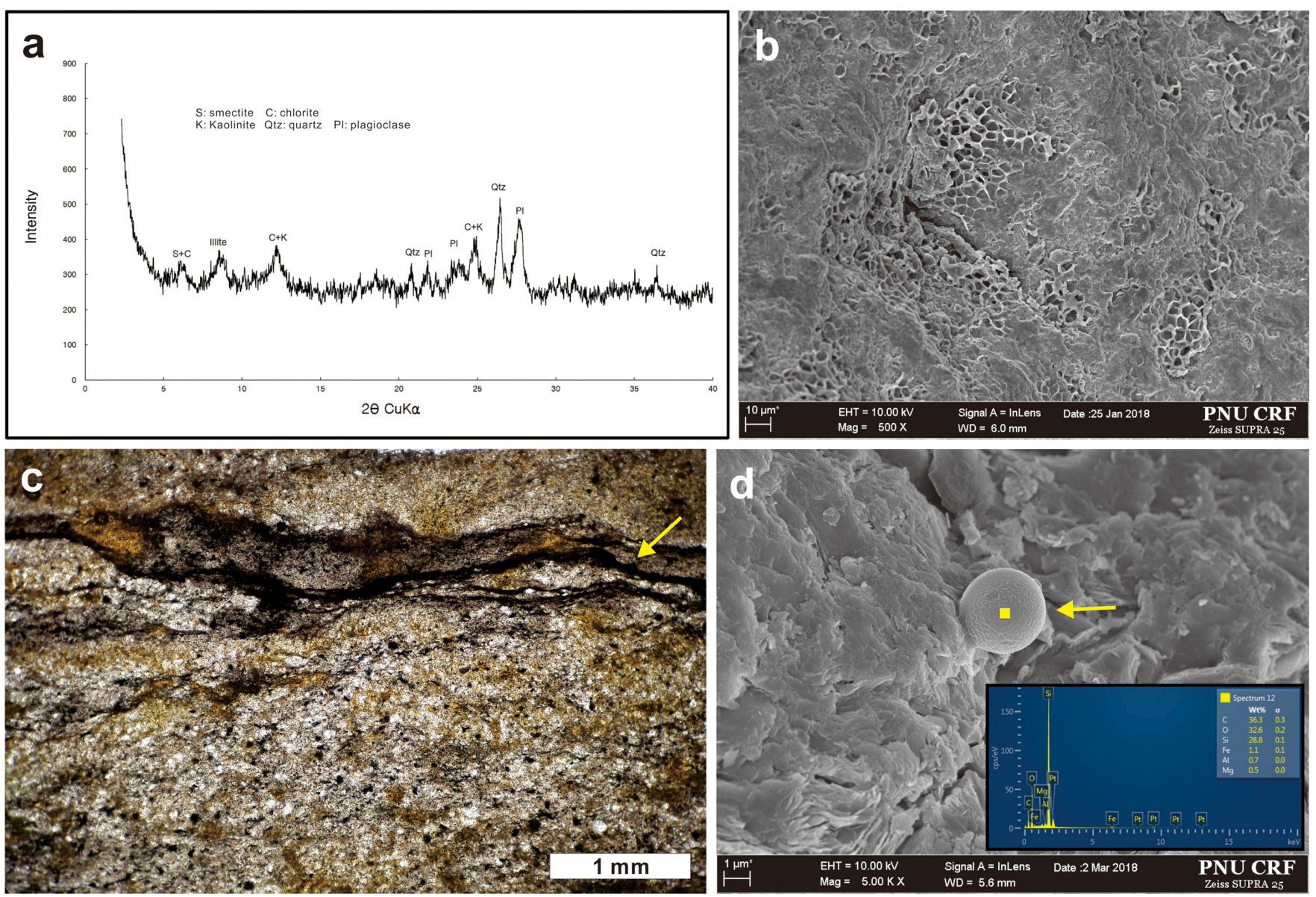

Figure 3. a. XRD result of the trackway-bearing deposit. b. FE-SEM photograph of the surface of the ornithopod footprint showing the honeycomb texture formed in smectitic clays. $c$. Thin section photomicrograh of the trackway-bearing deposit showing the presence of thin wisps of organic materials (arrow). d. FE-SEM photograph of the surface of the ornithopod footprint showing the presence of a globular microbe (arrow). EDS analysis (inset) for microbe shows the presence of organic matter. 
Table 1. Measurement of the trackways observed in study area. L: length of footprint, $W$ : width of footprint, P: pace, S: stride, PA: pace angle

\begin{tabular}{|c|c|c|c|c|c|c|}
\hline No. & & $\mathrm{L}(\mathrm{cm})$ & $\mathrm{W}(\mathrm{cm})$ & PL (cm) & $\mathrm{SL}(\mathrm{cm})$ & $\mathrm{PA}\left({ }^{\circ}\right)$ \\
\hline \multirow{3}{*}{$\mathrm{TOa}$} & 1 & 36.5 & 28.5 & 67.5 & 122.0 & \\
\hline & 2 & 34.0 & 25.5 & 57.0 & & 160.0 \\
\hline & 3 & 36.5 & 28.0 & & & \\
\hline Mean & & 35.7 & 27.3 & 62.3 & 122 & 160 \\
\hline \multirow{8}{*}{ TOb-1 } & 1 & & & & & \\
\hline & 2 & 35.0 & 28.0 & 85.0 & 146.8 & \\
\hline & 3 & 37.5 & 32.0 & 65.5 & 145.5 & 154.5 \\
\hline & 4 & 36.0 & 32.0 & 81.0 & & 170.0 \\
\hline & 5 & 35.0 & 26.0 & & & \\
\hline & 6 & & & & & \\
\hline & 7 & 33.0 & 31.0 & & & \\
\hline & 8 & & & & & \\
\hline Mean & & 35.3 & 29.8 & 77.2 & 146.2 & 162.3 \\
\hline \multirow[t]{10}{*}{ TOb-2 } & 1 & & 31.5 & 75.5 & 137.0 & \\
\hline & 2 & 33.0 & & 73.5 & 146.5 & 156.5 \\
\hline & 3 & 40.0 & 27.5 & 74.0 & 137.5 & 165.0 \\
\hline & 4 & 40.5 & 25.5 & 65.5 & & 166.5 \\
\hline & 5 & 32.0 & 30.0 & & & \\
\hline & 6 & & & & & \\
\hline & 7 & & & & & \\
\hline & 8 & & & 67.3 & 135.5 & \\
\hline & 9 & 34.0 & 30.0 & 70.5 & & \\
\hline & 10 & 34.0 & 30.0 & & & 165.0 \\
\hline Mean & & 35.6 & 29.1 & 71.05 & 139.1 & 163.25 \\
\hline \multirow[t]{10}{*}{ TOb-3 } & 1 & & & 77.5 & & \\
\hline & 2 & 36.0 & 30.5 & 74.5 & 138.0 & 166.5 \\
\hline & 3 & 39.0 & 30.5 & 65.5 & 141.0 & 162.0 \\
\hline & 4 & 39.0 & 34.5 & 77.0 & & 161.5 \\
\hline & 5 & & & & & \\
\hline & 6 & 36.0 & 29.5 & 82.0 & 155.2 & \\
\hline & 7 & 37.5 & 33.0 & 77.3 & 157.3 & 161.0 \\
\hline & 8 & 37.5 & 32.0 & 82.5 & & 154.5 \\
\hline & 9 & 36.5 & 31.0 & & & 159.5 \\
\hline & 10 & & & & & \\
\hline Mean & & 37.4 & 31.6 & 76.6 & 147.9 & 160.8 \\
\hline \multirow[t]{9}{*}{ TOc-1 } & 1 & 31.5 & 30.5 & 75.0 & & \\
\hline & 2 & 33.5 & 28.0 & 107.8 & & \\
\hline & 3 & 34.0 & 30.0 & & & \\
\hline & 4 & & & & & \\
\hline & 5 & 37.5 & 35.0 & 74.5 & & \\
\hline & 6 & 35.5 & 31.5 & 72.3 & & 172.0 \\
\hline & 7 & 35.0 & 29.5 & 76.8 & & 170.5 \\
\hline & 8 & 34.0 & 30.5 & & & \\
\hline & 9 & & & & & \\
\hline Mean & & 34.4 & 30.7 & 74.7 & & 171.3 \\
\hline
\end{tabular}

Table 1. Continued

\begin{tabular}{|c|c|c|c|c|c|c|}
\hline No. & & $\mathrm{L}(\mathrm{cm})$ & $\mathrm{W}(\mathrm{cm})$ & PL $(\mathrm{cm})$ & $\mathrm{SL}(\mathrm{cm})$ & PA $\left({ }^{\circ}\right)$ \\
\hline \multirow[t]{9}{*}{ TOc-2 } & 1 & & & & & \\
\hline & 2 & & & & & 166.5 \\
\hline & 3 & & & & & \\
\hline & 4 & & & & & \\
\hline & 5 & & & & & 163 \\
\hline & 6 & 33.5 & 27.5 & 52.7 & & 175.0 \\
\hline & 7 & 30 & 27.5 & & 94.0 & \\
\hline & 8 & & & 48.0 & & \\
\hline & 9 & 31.5 & 28.5 & & & \\
\hline Mean & & 31.7 & 27.8 & 50.3 & 84 & 168.2 \\
\hline \multirow[t]{3}{*}{$\mathrm{TTa}$} & 1 & & & & & \\
\hline & 2 & & & 120.5 & & 171.5 \\
\hline & 3 & 26.5 & 17.5 & & 243.0 & \\
\hline Mean & & 26.4 & 17.5 & 120.5 & 243 & 171.5 \\
\hline $\mathrm{TTb}$ & 1 & 34.3 & 21.5 & & & \\
\hline Mean & & 34.3 & 21.5 & & & \\
\hline
\end{tabular}

footprint (Figs. 4a-f, 5). The polygons are mostly approximately 1 to $2 \mathrm{~cm}$ in diameter, and they vary in surface morphology: subrhombic polygons with flattened ridges, irregular or regular polygons with flattened or pointed ridges, and subcircular polygons with rounded ridges (Fig. 5). Most of the polygons are subrhombic, and they are slightly elongated in general along the walking direction. Elongated sublinear ridges along the walking direction are also observed in the heel pads of some footprints. Hexagonal structures being characteristic of dinosaur skin texture are preserved in places.

Their selective occurrence in the footprints and their variations between footprints of the same trackway suggest that they are the transformed skin impressions of foot pads formed by walking on slightly slippery, viscous smectitic muds with microbes. Microbial biofilm-coated smooth muddy surface a few millimeters thick overlying sand has been documented as a suitable medium for the preservation of the foot pad skin texture on the footprint (Paik et al., 2017). Asymmetrical depressions with soft sediment deformation structures and brecciation are observed in the layers underlying the footprints (Fig. 6). This feature indicates that the substrate was hydroplastic and quasi-solid so that it preserved skin textures on the footprints when dinosaurs moved. The repetition of swelling and shrinkage of the smectitic muds due to alternation of wetting and drying conditions might have influenced the subsequent transformation of the skin impressions. The preservation of skin textures in every footprint observed in this site suggests that the multiple ornithopod trackways with subparallel orientation were imprinted nearly simultaneously, implying truly gregarious behavior of ornithopods.

Most of the multiple subparallel trackways documented to date are composed of more than three or four trackways by the same kinds of animals with regular inter-trackway spacing (Lockley et al, 2002; Hwang et al., 2004; Lockley et al., 2006; Lockley et al., 2012b). In contrast the multiple trackways at this site were formed by three kinds of ornithopods. They consist of one solitary trackway (TOa), coupled trackways (TOb2 and TOb3) with one overlapped solitary trackway (TOb1), 

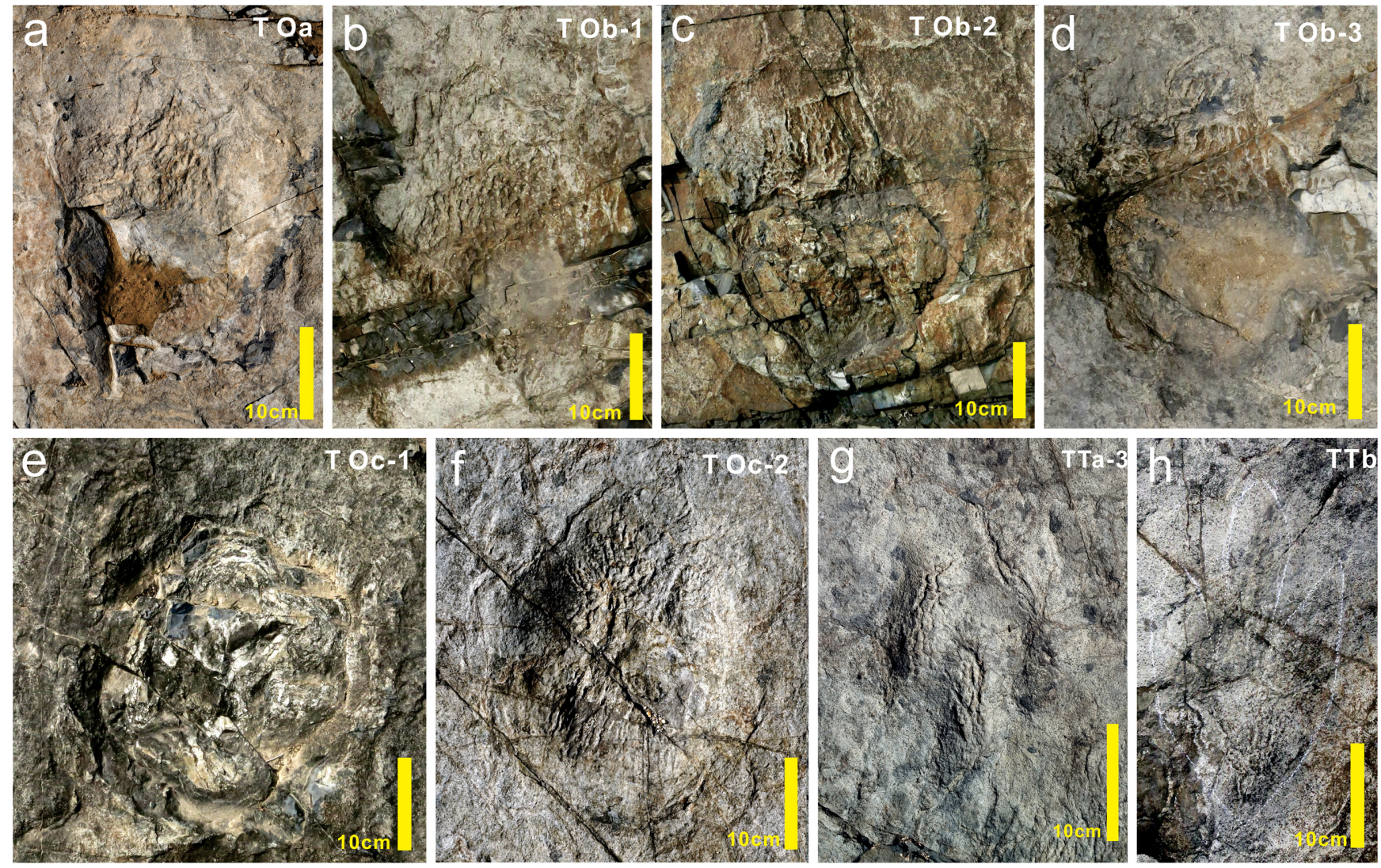

Figure 4. Footprints with partially transformed skin impressions of ornithopod trackways (a-f) and theropod trackways (g,h) in study area.

and another pair of trackways (TOc1 and TOc2) (Fig. 1d). In addition, the inter-trackway spaces between the different kinds are wider than those of the same kinds (Fig. 1). These trackways imply that movement of one or two animals occurred in the ornithopod group. Furthermore, they suggest that the different kinds of dinosaurs moved together at some lateral distance from each other in contrast to the laterally close movement of the same kinds. At the end of the trackways TOb another ornithopod trackway crosses them. No skin impressions appear in its footprints, indicating that it was formed later under low water-saturated conditions after prolonged exposure.

In trackways $\mathrm{TOb}$, intricate records are observed in the relation among TOb1, TOb2, and a theropod's trackway closely associated with TOb1. The first two footprints of TOb2 are partially overlapped by TOb1. Whereas TOb2 and TOb3 show a uniform trackway direction, TOb1 deviates to the left from the second footprint into the third one and deviates again into the former direction being parallel to TOb2 and TOb3. The overlapping of the first two footprints of TOb1 on TOb2 and very close inter-trackway spacing afterwards between TOb1 and $\mathrm{TOb} 2$ indicate that TOb1 was formed shortly after TOb2 and TOb3 were simultaneously made. One trackway (TTa) by a theropod is closely associated in the left side of TOb1. TTa is oriented in the opposite direction to $\mathrm{TOb}$ and its strides are nearly twice as much as those of TOb (Fig 1d, Table 1). Whereas TTa1 and TTa2 are indistinct, TTa3 between the first and the second footprints of TOb1 is a distinct footprint with transformed skin impression (Fig. 4g). In the middle area between TOb3 and TOc1 one indistinct footprint from another kind of theropod (TTb) is present (Fig. 4h).

\section{Interpretation}

These trackway occurrences provide us with an understanding of dinosaur hunting as follows. Various kinds of ornithopods gathered around a lake margin with little vegetation to drink water during a drought season in a quiescent stage of volcanic activity. During their return, one ornithopod (TOb1) following behind its family was isolated and became the target of a single theropod's hunting (Fig. 7). The theropod (TTa) encountered the ornithopod from the opposite direction and attacked the ornithopod. The ornithopod staggered for a second because of the attack, but did not fall to the ground, and continued moving in the same direction. Consequently, the theropod's solitary hunting failed.

Due to the difficulty of interpreting the timing of track-making, a number of multiple dinosaur trackways (Pittman, 1989; Hornung et al., 2016) and co-occurrences of herbivorous dinosaurs' tracks with theropods' footprints (Thulborn and Wade, 1984; Huh et al., 2006; Xing et al., 2017) documented around the world cannot provide convincing evidence to indicate gregarious movement of dinosaurs and theropods' hunting for herbivorous dinosaurs respectively. Although trackways with subparallel orientations and close associations of theropods' footprints with herbivorous dinosaurs' tracks are not rare in Korea (Lockley et al., 2006; Paik et al., 2013; Kim et al., 2019), records supporting concurrence of the track formation and the preservation of skin impressions in every trackway have never been observed except in the trackways documented in this study. In this aspect the presence of transformed skin impressions with similar patterns on every footprint of the sub- 

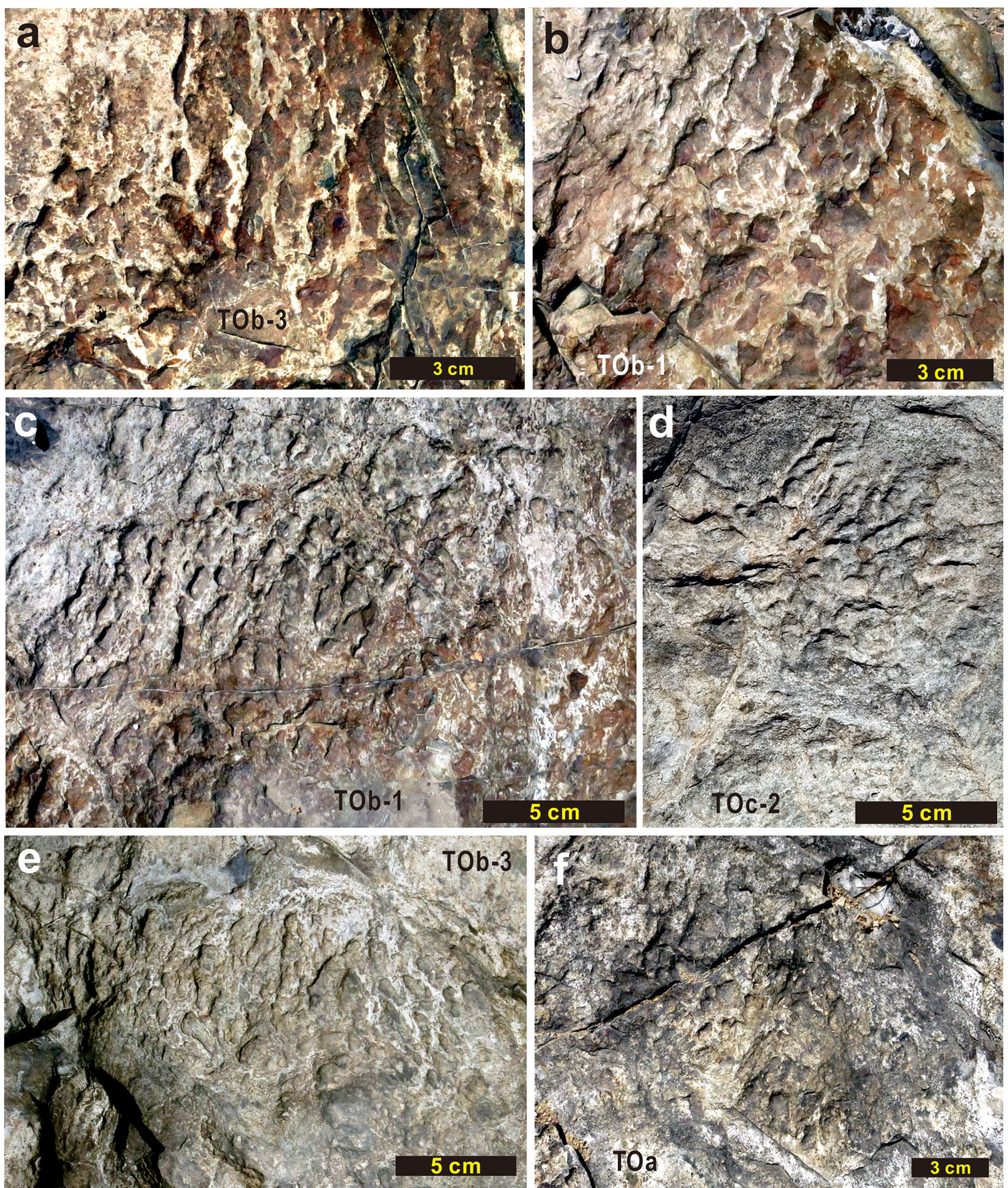

Figure 5. Diverse fabrics of the transformed skin impressions in the ornithopod footprints in study area.

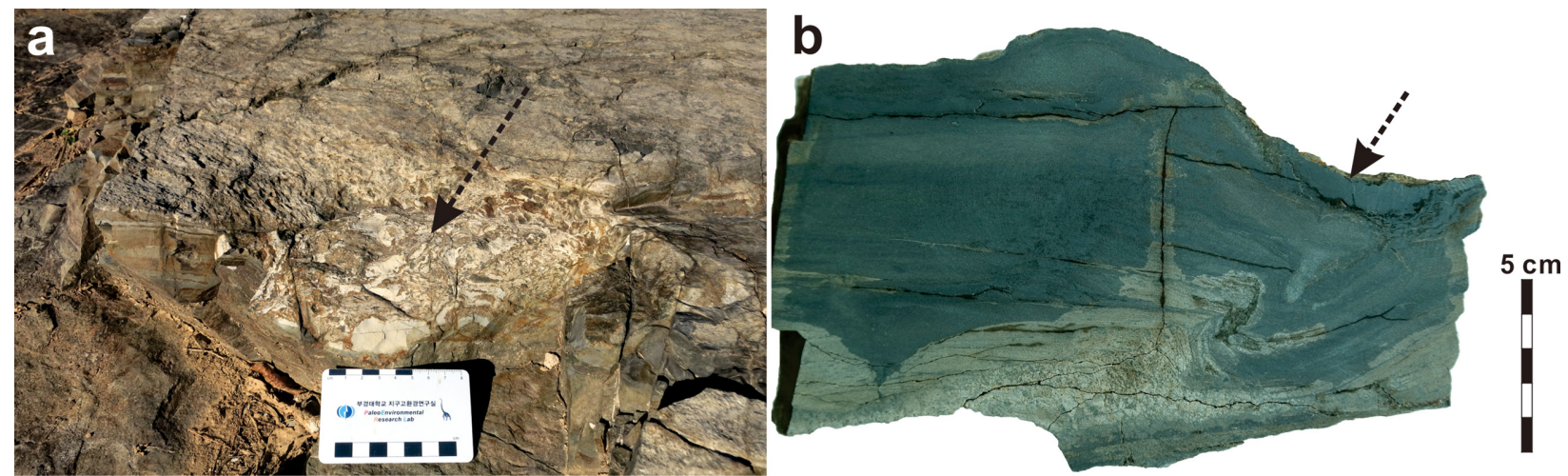

Figure 6. Brecciation (arrow) of the trampled deposit (a) and hydroplastic deformation below the trampled surface (arrow) (b). a is an oblique view to the surface and $b$ is a sectional view. 


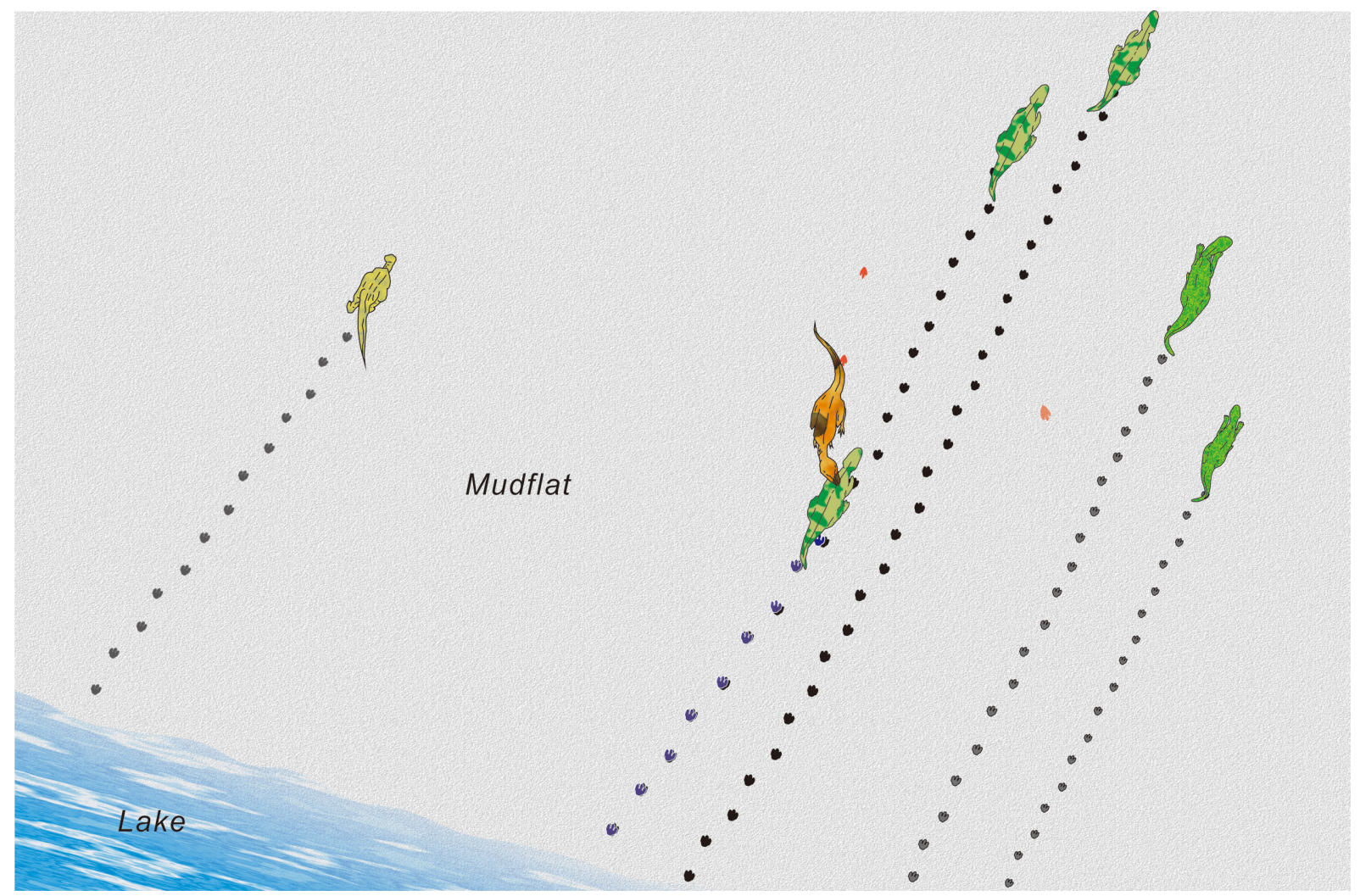

Figure 7. Schematic reconstruction of the snapshot interpreted from the trackway occurrences in study area.

parallel multiple trackways and the closely associated theropod footprints exposed in this tracksite combine to produce an extremely rare record that indicates truly gregarious behavior of ornithopods and solitary hunting for herbivorous dinosaurs by theropods.

\section{Conclusions}

The Yugok-dong tracksite is very exceptional not only in preserving skin impressions in every footprint (approximately 80 ) of six subparallel trackways but also in providing new evidence to support that different kinds of herbivorous dinosaurs moved together in the same direction to form a group. In addition, Yugok-dong tracksite suggests that movements in pairs or solo were included in ornithopods' group movement and that solitary hunting was also present in non-avian dinosaurs as in modern tigers or leopards (Roach and Brinkman, 2007). Consequently, a lake margin on a floodplain is interpreted to have been exploited as a vital ecosite for dinosaurs during a drought season, similar to a modern savannah.

\section{Acknowledgements}

This work was supported by the KRF Research Grant (NRF2018R1D1A1B07041872). We are grateful to two anonymous reviewers for their constructive and thoughtful reviews, which improved the final version of the manuscript. We are also grateful to Jung-gu District, Ulsan Metropolitan City for the permit to the Yugok-dong tracksite. Thanks are extended to Mr. Jung Gyu Park for his help in the field work.

\section{References}

Choi, H.I., 1985, Sedimentology and its implications for stratigraphic classifications of the Cretaceous Gyeongsang Basin. Journal of Geological Society of Korea, v. 21, pp. 26-37.

Falkingham, P.L., Marty, D., and Richter, A., 2016, Dinosaur Tracks: The next step. Indiana University Press, Indiana, $428 \mathrm{p}$.

Fastovsky, D.E., and Smith, J.B., 2004, Dinosaur Paleoecolgy. In: Weishampel, D.B., Dodson, P., and Osmólska, H. (Eds.), The Dinosauria (2nd edition). University of California Press, California, pp. 614-626.

Horner, J.R., 1982, Evidence of colonial nesting and 'site fidelity' among ornithischian dinosaurs. Nature, v. 297, pp. 675-676.

Hornung, J.J., Bőhme, A., Schlüter, N., and Reich, M., 2016, Diversity, Ontogeny, or Both?: A Morphometric Approach to Iguanodontian Ornithopod (Dinosauria: Ornithischina) Track assemblages from the Berriasian (Lower Cretaceous) of Northwestern Germany. In: Falkingham, P.L., Marty, D., Richter, A. (Eds.), Dinosaur Tracks: The next step. Indiana University Press, Bloomington and Indianapolis, pp. 202-225.

Huh, M., Paik, I.S., Lockley, M.G., Hwang, K.G., Kim, B.S., and Kwak, S. K., 2006, Well-preserved theropod tracks from the Upper Cretaceous Hwasun County, southwestern South Korea, and their paleobiological implications. Cretaceous Research, v. 27, pp. 123-138.

Hwang, K.G., Huh, M., and Paik, I.S., 2004, Sauropod trackways from the Cretaceous Jindong Formation at Docheon-ri, Changnyeong-gun, Gyeongsangnam-do, Korea. Journal of Geological Society of Korea, v. 40, pp. $145-159$.

Jasinski, L.E., 2008, Dinosaur Highway: A history of Dinosaur Valley State Park. Texas Christian University Press, Texas, 212 p.

Kim, H.J., Hwang, G.K., Jeong, H.H., Ahn, H.Y., Choi, C.U., Lim, H.S., Choi, T., Chae, Y.U., and Paik, I.S., 2019, Dinosaur track-bearing deposits in Sagok Formation (Cretaceous) at Sinseong-ri, Cheonsong-gun, Korea: Occurrences and paleoenvironments. Journal of Geological Society of Korea, v. 55, pp. 495-511. 
Li, R., Lockley, M.G., Makovicky, P.J., Matsukawa, M., Norell, M.A., Harris, J.D., and Liu, M., 2008, Behavioral and faunal implications of Early Cretaceous deinonychosaur trackways from China. Naturwissenschaften, v. 95, pp. 185-191.

Lim, S.-Y., Yang, S.-Y., and Lockley, M.G., 1989, Large dinosaur footprint assemblages from the Cretaceous Jindong Formation of southern Korea. In: Gillette, D.D., and Lockley, M.G. (Eds.), Dinosaur Tracks and Traces. Cambridge University Press, Cambridge, pp. 333-336.

Lockley, M.G., Holbrook, J., Hunt, A.P., Matsukawa, M., and Meyer, C., 1992, The dinosaur freeway: a preliminary report on the Cretaceous megatracksite, Dakota Group, Rocky Mountain Front Range and Highplains; Colorado, Oklahoma and New Mexico. In: Flores, R. (Ed.), Mesozoic of the Western Interior. Society of Economic Paleontologists and Mineralogists, Tulsa, OK, Midyear Mtg. Fieldtrip Guidebook, pp. 39-54.

Lockley, M.G., 1997, The paleoecological and paleoenvironmental utility of dinosaur tracks. In: Farlow, J.O., and Brett-Sorman, M.K. (Eds.), The Complete Dinosaur. Indiana University Press, Bloomington and Indianapolis, pp. 554-578.

Lockley, M.G., Schulp, A.S., Meyer, C.A., Leonardi, G., and Mamani, D.K., 2002, Titanosaurid trackways from the Upper Cretaceous of Bolivia: evidence for large manus, wide-gauge locomotion and gregarious behavior. Cretaceous Research, v. 23, pp. 383-400.

Lockley, M. G., Houck, K., Yang, S.-Y., Matsukawa, M., and Lim, S.-K., 2006, Dinosaur dominated footprint assemblages from the Cretaceous Jindong Formation, Hallayo Haesang National Park, Goseong County, South Korea: Evidence and implications. Cretaceous Research, v. 27, pp. $70-101$.

Lockley, M.G., Huh, M., Kim, J.Y., Lim, J.D., and Kim, K.S., 2012a, Recent Advances in Korean vertebrate ichnology: The KCDC comes of Age. Ichnos, v. 19, pp. 1-5.

Lockley, M.G., Huh, M., Gwak, S.-G., Hwang, K.G., and Paik, I.S., 2012b, Multiple tracksites with parallel trackways from the Cretaceous of the Yeosu City Area Korea: Implications for gregarious behavior in Ornithopod and Saurpod dinosaurs. Ichnos, v. 19, pp. 105-114.

McCrea, R.T., Buckley, L.G., Farlow, J.O., Lockely, M.G., Currie, P.J., Matthews, N.A., and Pemberton, S.G., 2014, A 'Terror of Tyrannosaurs': The first trackways of Tyrannosaurids and evidence of gregariousness and pathology in Tyrannosauridae. Plos One, v. 7, e103613.

Myers, T.S., and Fiorillo, A.R., 2009, Evidence for gregarious behavior and age segregation in sauropod dinosaurs. Palaeogeography, Palaeoclima-

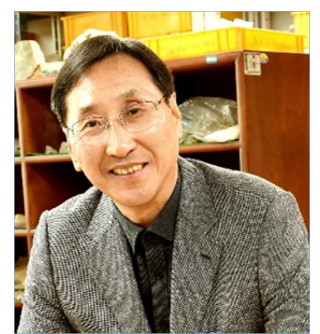

In Sung Paik is a Professor of Sedimentary Geology in Department of Earth and Environmental Sciences, Pukyong National University, Busan, Korea. He received his Ph.D. in Geology from Seoul National University, Korea. He served as the Vice-president of the Geological Society of Korea (2010-2011) and Regional coordinator of IGCP 608. During a couple of decades his research has focused on the taphonomy, paleoecology, and paleoenvironments of the Cretaceous continental deposits of Korean Peninsula. His another current research interests are on the geological heritages and Geoparks in Korea

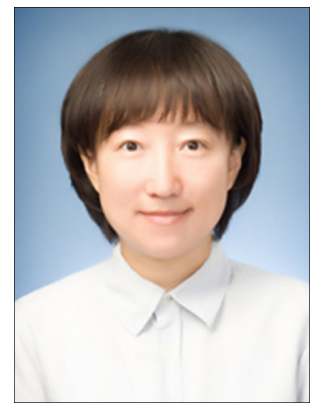

Hyun Joo Kim is a lecturer and postdoctoral researcher of sedimentary geology in Department of Earth and Environmental Sciences, Pukyong National University, Busan, Korea. She received her Ph.D. from Department of Earth and Environmental Sciences, Pukyong National University, Korea. She has studied paleoenvironments and taphonomy of the fossil-bearing deposits from Cretaceous sedimentary basins in Korea. tology, Palaeoecology, v. 274, pp. 96-104.

Paik, I.S., Kim, H.J., Kang, H.C., and Lim, J.D., 2013, Dinosaur Tracksite at Jeori, Geumseongmyeon, Euiseonggun, Gyeongsandbukdo, Korea (National Monument No. 373) (in Korean). Munhwajae Korean Journal of Cultural Heritage Studies, v. 46, pp. 268-289.

Paik, I.S., Kim, H.J., Lee, H., and Kim, S., 2017, A large and distinct skin impression on the cast of a sauropod dinosaur footprint from Early Cretaceous floodplain deposits, Korea. Scientific Reports, v. 7, p. 16339.

Pittman, J.G., 1989, Stratigraphy, lithology, depositional environment, and track type of dinosaur track-bearing beds of the Gulf Coastal Plain. In: Gillette, D.D., and Lockley, M.G. (Eds.), Dinosaur Tracks and Traces. Cambridge University Press, Cambridge, pp. 155-163.

Pittman, J.G., and Gillette, D.D., 1989, The Briar Site: a new sauropod dinosaur tracksite in Lower Cretaceous beds of Arkansas, USA. In: Lockley, M.G., and Gillette, D.D. (Eds.), Dinosaur Tracks and Traces. Cambridge University Review, New York, pp. 313-332.

Razzolini, N.L., Oms, O., Castanera, D., Vila, B., dos Santos, V. F., and Galobart, À., 2016, Ichnological evidence of Megalosaurid Dinosaurs Crossing Middle Jurassic Tidal Flats. Scientific Reports, v. 6, p. 31494. doi:10.1038/srep31494

Roach, B., and Brinkman, D., 2007, A reevaluation of cooperative pack hunting and gregariousness in Deinonychus antirrhopus and other nonavian theropod dinosaurs. Bulletin of the Peabody Museum of Natural History, v. 48, pp. 103-138.

Rogers, R.R.,1990, Taphonomy of three dinosaur bone beds in the Upper Cretaceous Two Medicine Formation of northwestern Montana; evidence for drought-related mortality. Palaios, v. 5, pp. 394-413.

Thulborn, R.A., and Wade, M., 1984, Dinosaur trackways in the Winton Formation (Mid-Cretaceous) of Queensland. Memoirs of the Queensland Museum, v. 21, pp. 413-717.

Xing, L., Lockley, M.G., Li, D., Klein, H., Ye, Y., Persons IV, W.S., and Ran, H., 2017, Late Cretacoues orinithopod-dominated theropod, and pterosaur track assemblages from the Nanzxiong Basin, China: New discoveries, ichnotaxonomy, and paleoecology. Palaeogeography, Palaeoclimatology, Palaeoecology, v. 466, pp. 303-313.

Zhao, Q., Barrett, P. M., and Eberth, D. A., 2007, Social behavior and mass mortality in the basal Ceratopsian dinosaur Psittacosaurus (Early Creatceous, People's Republic of China). Paleontology, v. 50, pp. 1023 1029.

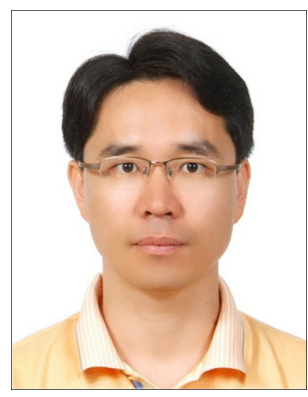

Seung Gyun Baek is the director of research institute in GEMATEK (Geo Marine Technology) Co. LTD. He received his Ph.D. in marine. geological remote sensing and GIS from Pukyong National University. He has studied coastal environmental changes and geological heritage conservation using remote sensing, GIS, UAV.

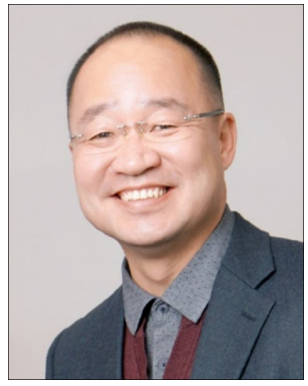

Young Kyo Seo is the CEO of a marine survey company (Geo Marine Technology Co. LTD). $\mathrm{He}$ received his $\mathrm{Ph} . \mathrm{D}$. in marine geology from Pukyong National University. Recently, he is interested in the investigation and analysis of changes in coastal topography using small drones, and monitoring fossil sites. 